\title{
Employer safety obligations, transformational leadership and their interactive effects on employee safety performance
}

\author{
Jane Mullen $^{\mathrm{a}, *}$, E. Kevin Kelloway ${ }^{\mathrm{b}}$, Michael Teed ${ }^{\mathrm{c}}$ \\ a Department of Commerce, Ron Joyce Center for Business Studies, Mount Allison University, Canada \\ ${ }^{\mathrm{b}}$ Department of Psychology, Saint Mary's University, Canada \\ ' Williams School of Business, Bishop's University, Canada
}

\section{A R T I C L E I N F O}

Article history:

Received 5 October 2015

Received in revised form 16 August 2016

Accepted 16 September 2016

Available online 23 September 2016

\section{Keywords:}

Safety obligations

Safety leadership

Safety performance

\begin{abstract}
A B S T R A C T
We examine the moderating effect of safety-specific transformational leadership on the relationship between perceived employer safety obligations and employee safety performance behavior and attitudes. Drawing on social exchange theory, and using data from a cross-sectional $(\mathrm{N}=115)$ and a longitudinal $(\mathrm{N}=140)$ sample of trade employees, we show that perceived employer safety obligations are positively associated with employee safety compliance, safety participation and attitudes. Safety-specific transformational leadership was positively and significantly associated with employee safety compliance, safety participation and safety attitudes. Leadership also acted as a moderator such that the relationships between perceived employer safety obligations and the safety outcomes (safety compliance, safety participation, safety attitudes) are stronger when safety-specific transformational leadership is high, as opposed to when low. We provide theoretical and practical implications stemming from this study and suggest directions for future research aimed at improving safety performance behavior and attitudes within organizations.
\end{abstract}

(c) 2016 Elsevier Ltd. All rights reserved.

\section{Introduction}

There is a growing interest in both organizational and leader influences on safety performance behavior (Katz-Navon et al., 2005; Nahrgang et al., 2007; Hofmann et al., 2003). Although it has been well established in the literature that leadership is an important antecedent of employee safety performance behavior in organizations (Clarke, 2013), little is known about the role leadership plays in predicting safety performance when combined with other organizational safety influences. One organizational safety influence that has recently been identified as being important for understanding safety performance is perceived safety obligations within organizations (Walker and Hutton, 2006), which are described as employee perceptions and beliefs about workplace safety responsibilities that may be derived from societal and organizational influences (Burt et al., 2012; Walker and Hutton, 2006).

Empirical evidence indicates that employees hold beliefs about safety obligations in their workplace (Walker, 2010). Drawing on

Support from the Social Sciences and Humanities Research Council to the first and second authors is gratefully acknowledged.

* Corresponding author at: Commerce Department, Ron Joyce Centre for Business Studies, Mount Allison University, 144 Main Street, Sackville, NB E4L 4H4, Canada.

E-mail address: jmullen@mta.ca (J. Mullen). psychological contract theory (Rousseau, 1989), social exchange theory (Blau, 1964) and the concept of reciprocity (Gouldner, 1960), Walker and Hutton (2006) demonstrated that employees will reciprocate perceived employer safety obligations with positive safety behavior. In contrast, when employees perceive that employers do not fulfill safety obligations, they are less obliged to reciprocate with positive safety behaviors or fulfill their perceived employee safety obligations. Walker and Hutton's (2006) research provides qualitative evidence of reciprocity between perceived employer and employee safety obligations. Similarly, reciprocity between management and employees has also been demonstrated in studies examining leader-member exchange and safety performance behavior such that employees reciprocate high quality relationships with their supervisor by engaging in positive safety behaviors (Hofmann and Morgeson, 1999; Hofmann et al., 2003).

The purpose of this research is to build on the notion of safety reciprocity between employers/leaders and employees to gain an understanding of how perceived employer safety obligations and safety transformational leadership affect employee safety performance behavior and attitudes. Specifically, this study advances prior research in several ways. First, we build on qualitative research by quantitatively examining the effects of perceived employer safety obligations on employees' safety performance 
behavior and attitudes. Second, we examine the main and interaction effects of perceived employer safety obligations and safety transformational leadership behavior on safety outcomes. We empirically evaluate the hypothesis that leaders who engage in safety transformational leadership enhance any positive effects of perceived employer safety obligations on employee safety performance behavior and attitudes. Third, using both cross-sectional and longitudinal designs, we base our analyses on two samples, one of trade apprentices and one comprised of community college trade students completing an on-the-job practicum. Empirically testing our hypotheses using different samples allows for a comparison of findings to determine if our expected outcomes remain stable across samples.

We focus on two types of safety performance behavior, namely, safety compliance and safety participation (Neal et al., 2000). Safety compliance involves carrying out required behaviors that maintain workplace safety such as following safety procedures and wearing protective safety equipment. Safety participation includes extra-role behaviors that indirectly contribute to developing a safe work environment such as voicing concerns about safety (Tucker and Turner, 2015), employee initiative to voluntarily participate in safety activities and programs (Cree and Kelloway, 1997), helping co-workers with safety problems, promoting the safety programs and policies, attending safety meetings (Neal et al., 2000). The important distinguishing factor between the two forms of safety performance behavior is that compliance involves in-role task-related behavior, whereas safety participation involves extra-role behaviors that are voluntary and initiated by employees (Clarke and Ward, 2006). Substantial empirical evidence demonstrates that both types of safety performance behavior are associated with fewer work-related accidents and injuries (see meta-analytic studies by Clarke, 2006, 2013).

Lastly, we are interested in employee safety attitudes, defined as an individual's beliefs and feelings about safety (Neal and Griffin, 2003). Safety attitudes reflect an employee's views about the importance of safety and should be distinguished from the well-researched concept of safety climate, which is described as shared perceptions of organizational safety practices and policies (Neal and Griffin, 2003, 2006; Zohar, 2000). The beliefs employees hold about workplace safety have been found to be shaped by nonwork social influences (i.e., parental safety attitudes) (Kelloway et al., 2005) and organizational influences (i.e., employee beliefs about management's concern for safety) (McLain, 2014).

\section{Perceived employer safety obligations}

Research based on social exchange theory (Blau, 1964) in the safety literature suggests that positive safety attitudes and behavior result through the reciprocation of social influences experienced within organizations (Hofmann et al., 2003; Hofmann and Morgeson, 1999). According to psychological contract theory (Rousseau, 1990), which draws on social exchange theory, the reciprocation of positive safety attitudes and behavior may also result from transactional (i.e., employer provides safety resources) and relational influences (i.e., employer concern for safety) within an organization (Walker, 2010). Employees develop beliefs or perceptions about employer safety obligations (and employee safety obligations to the employer) during the term of employment (Walker and Hutton, 2006). When employers fulfill safety-related obligations and transactional responsibilities, such as providing safety training and properly maintaining equipment, it signals to employees that their safety and well-being is valued within the organization. Perceived organizational priority on safety and concern for employee well-being may be considered an implied obli- gation for employees to reciprocate safe work behaviors (Hofmann and Morgeson, 1999; Kath et al., 2010). Nahrgang et al.'s (2007) meta-analysis of safety antecedents and outcomes showed a positive relationship between organizational safety activities (i.e., opportunities aimed at enhancing employee safety knowledge, safety leadership, and social support) and employee safety behavior, providing support for the notion of safety reciprocity between employers and employees.

Hypothesis 1a. Perceived employer safety obligations are positively associated with safety compliance.

Hypothesis 1b. Perceived employer safety obligations are positively associated with safety participation.

Hypothesis 1c. Perceived employer safety obligations are positively associated with safety attitudes.

\section{Transformational leadership and safety performance behavior}

There is a growing body of evidence supporting the positive association between transformational leadership (Bass, 1985) and employee safety performance behavior (Clarke, 2013). Behaviors that are characteristic of transformational leadership have been shown to be associated with both employee safety participation and compliance. Clarke's (2013) meta-analysis showed that both transformational and transactional leadership were significantly associated with safety compliance and participation. The data indicate that transformational leadership has a stronger association with safety participation than with safety compliance. Similarly, results from a meta-analysis by Christian et al. (2009) showed that leaders have a stronger influence on employee safety participation than safety compliance.

The relationship between the specific facets of transformational leadership and employee safety behavior has also been examined. For example, through leader-employee social interactions, employees observe their leader's behavior and interpret such behavior as being reflective of the priority the leader places on safety (Zohar and Tenne-Gazit, 2008). Results from a randomized intervention field study conducted by Zohar and Polachek (2014) suggest that when leaders communicate the safety priorities in daily meetings (characteristic of transformational leadership), employee reports of perceived priority of safety increase, and subsequently perceptions of safety climate level and employee safety behavior increase (Zohar and Polachek, 2014). Hoffmeister et al. (2014) examined the impact of the facets of transformational and transactional leadership on apprentice and journeymen safety behavior. The results showed that idealized influence (i.e., evoking trust, respect, being a role model of safety) predicted safety compliance behavior in both the apprentice and journeymen samples. In terms of safety participation, idealized influence, inspirational motivation (i.e., communicate vision for safety, inspire safety behavior) and contingent reward predicted apprentice safety participation. In the journeymen sample, the results showed that the global measure of leadership predicted safety participation and no specific facet of transformational leadership was influential on safety participation. The research suggests that transformational leadership, particularly idealized influence, is an important determinant of both safety compliance and safety participation.

Hypothesis 2a. Perceived safety transformational leadership will be positively associated with safety compliance. 
Hypothesis 2b. Perceived safety transformational leadership will be positively associated with safety participation.

Hypothesis 2c. Perceived safety transformational leadership will be positively associated with safety attitudes.

The combined influences of leader safety behavior and employee perceptions of organizational safety-related practices on employee safety performance have also been examined. Evidence suggests that safety performance behaviors are enhanced when leader safety practices are combined with a high perceived organizational priority on safety (Katz-Navon et al., 2005). Transformational leadership behavior has been found to influence the relationship between group and organizational safety climates (i.e., shared perceptions of workplace safety policies, procedures, and practices), such that transformational leadership behavior buffers the negative effects of poor organizational safety climate on group members (Zohar and Luria, 2010). We anticipated that transformational safety leadership behavior would enhance the positive safety performance outcomes expected when employees perceive that safety obligations have been fulfilled.

Previous research shows that when leaders place a strong emphasis on safety it leads to increased employee safety motivation, safety compliance and safety participation (Neal and Griffin, 2006). Thus, we expect that the positive safety outcomes achieved through employer safety obligations will be enhanced when leaders communicate their values and beliefs of the importance of safety and demonstrate commitment to safety through their behavior.

Hypothesis 3a. Safety-specific transformational leadership moderates the relationship between workers' perceptions of employer safety obligations and safety compliance. The relationship is stronger when safety-specific transformational leadership is high compared to when safety-specific transformational leadership is low.

Hypothesis 3b. Safety-specific transformational leadership moderates the relationship between workers' perceptions of employer safety obligations and safety participation. The relationship is stronger when safety-specific transformational leadership is high compared to when safety-specific transformational leadership is low.

Hypothesis 3c. Safety-specific transformational leadership moderates the relationship between workers' perceptions of employer safety obligations and safety attitudes. The relationship is stronger when safety-specific transformational leadership is high compared to when safety-specific transformational leadership is low.

To summarize, we empirically evaluate the hypothesis that leaders who engage in safety transformational leadership enhance any positive effects of perceived employer safety obligations on employee safety performance behavior and attitudes. We test our hypotheses about the main and combined effects of perceived employer safety obligations and safety transformational leadership. All hypotheses are examined in a sample of apprentices, and again in a sample comprised of individuals completing an on-the-job practicum in their respective trade.

\section{Method}

\subsection{Participants and procedure}

Data for this study were collected from two samples. Sample A includes ( $\mathrm{n}=125$ ) trade apprentices (truck and transport services, machinist, electrical, metals, heavy equipment technician, automo- tive service technician, boiler maker, and mechanic). Apprentices were contacted through a community college located in Eastern Canada and invited to complete a survey. Due to missing data, we removed 10 cases resulting in a final sample of 115 apprentices (all male, $\mathrm{M}_{\mathrm{age}}=27.6$ years, $\mathrm{SD}=7.97$ ).

Sample B consisted of community college students enrolled in one year certificate programs that included a four-week industry practicum. Participants were from twenty different certificate programs (Automotive Service \& Repair, Civil Engineering Technology, Continuing Care, Culinary, Construction Management, Medical Lab Technician, Motorcycle \& Power Products and Repair, Office Administration, Pipe Trades, Welding, Heavy Equipment Service Technician, Sheet Metal Fabrication, Motor Vehicle Body Repair, Machining, Automotive Collision Repair and Refinishing, Heavy Duty Truck and Transport Repair, Electrical, Steel Fabrication, Carpentry, Truck and Transport Service Technician). The community college is also located in Eastern Canada but in a different province than the college described above. Data were collected at two periods during the one year certificate program. The Time 1 survey measuring safety compliance, safety participation and safety attitudes was administered at the end of the in-class component of the program in April. Participants completed the Time 2 survey after completing a four week industry practicum to assess safetyrelated experiences during their employment. The time 2 survey included measures of perceived employer safety obligations, safety-specific transformational leadership, safety compliance, safety participation, and safety attitudes. All participants completed industry practicums with employers located within Eastern Canada.

Of the 377 participants who completed the survey at Time 1 and 199 at Time 2, 140 participants were successfully matched (9 females, 131 males). The average age of participants was 22 years $(S D=5.5)$. There were no significant differences in demographic characteristics between participants who were matched on the Time 1 and Time 2 data and participants who did not have data for both surveys.

\subsection{Measures}

Participants from sample A and sample B completed the same measures. All items for each measure, with the exception of perceived employer safety obligations, were rated using a 7-point response scale ( $1=$ strongly disagree to $7=$ strongly agree). Items for the perceived employer safety obligations were rated using a 7 -point scale ( $1=$ not at all fulfilled to 7 = completely fulfilled).

\subsubsection{Perceived employer safety obligations}

Drawing on Walker's (2010) measure, we developed 11 items to assess perceived employer safety obligations. (Sample A $\alpha=0.94$; Sample B at Time $2 \alpha=0.94$ ). Exploratory principal axis factor analysis in sample A resulted in the extraction of one factor accounting for $63 \%$ of item variance. All items loaded substantially $(>0.70)$ on the factor. For Sample B at Time 2, one factor accounting for $61 \%$ of item variance was extracted. Again, all items loaded substantially $(>0.70)$ on the factor. In developing items for the scale, we focused on the transactional (as opposed to relational) employer obligations (Walker, 2010). A sample item includes "equipment is maintained and properly functioning". All items are provided in Table 1.

\subsubsection{Safety-specific transformational leadership}

Employee perceptions of supervisory safety-specific transformational leadership behaviors were assessed with Barling et al.'s (2002) 10-item measure. The 10-item scale was adapted from the MLQ-5 (Bass and Avolio, 1997). (Sample A $\alpha=0.94$; Sample B at Time $1 \alpha=0.92$; Sample B at Time $2 \alpha=0.96$ ). A sample item 
Table 1

Items for the perceived employer safety obligation measure.

1. Provided me with safety training

2. Showed me how to prevent accidents

3. Pointed out aspects of the job that could potentially harm me

4. Taught me how to respond to emergency situations

5. Prevented me from carrying out potentially dangerous work

6. Prevented me from performing a task that I have not been properly trained to do

7. Taught me how to properly use equipment and machinery

8. Ensured that my co-workers were properly trained before performing a job

9. Monitored the safety behavior of my co-workers to ensure they do not injure someone

10. Implemented safety policies and practices

11. Ensured the equipment is maintained and properly functioning

includes "My supervisor talks about his/her values and beliefs of the importance of safety".

\subsubsection{Safety participation}

Employee perceptions of safety participation were assessed using Neal et al.'s (2000) 4-item safety participation scale. (Sample A $\alpha=0.85$; Sample B at Time $1 \alpha=0.80$; Sample B at Time 2 $\alpha=0.81$ ). A sample item includes "I put in extra effort to improve the safety of the workplace".

\subsubsection{Safety compliance}

Employee perceptions of safety compliance were assessed by Neal et al.'s (2000) 4-item safety compliance scale. (Sample A $\alpha=0.88$; Sample B at Time $1 \alpha=0.91$; Sample B at Time 2 $\alpha=0.92$ ). Examples of items include "I use all the necessary safety equipment to do my job", and "I use the correct safety procedures for carrying out my job".

\subsubsection{Safety attitudes}

Employee safety attitudes were assessed with Kelloway et al.'s (2005) 11-item measure. (Sample A $\alpha=0.92$; Sample B at Time 1 $\alpha=0.91$; Sample B at Time $2 \alpha=0.91$ ). A sample item includes "I really believe in working safely at all times".

\subsubsection{Control variables}

For Sample A we controlled for age. We did not control for gender as all participants were male. In Sample B we controlled for age, gender and Time 1 measures of safety compliance, safety participation, and safety attitudes.

We conducted moderated regression analyses predicting safety compliance, safety participation, and safety attitudes using the Process macro for SPSS (Hayes, 2013). To test the moderating effect of safety-specific transformational leadership, we entered the safety performance behaviors and attitude variables as the outcome variables in separate analyses. The remaining variables were entered in subsequent steps (control variables, followed by perceived employer safety obligations and safety-specific transformational leadership), and the interaction term (perceived employer safety obligations $\times$ safety-specific transformational leadership).
For the analysis of Sample B data, Time 1 measures of safety compliance, safety participation and safety attitudes were entered in the analysis as control variables. Age and gender were also entered as control variables. For both samples, the main effects of employer obligations and safety-specific transformational leadership were centered prior to computation of the interaction term. The results of these analyses are shown in Table 2.

\section{Results}

Descriptive statistics and intercorrelations between study variables for both samples are presented in Table 2 .

Perceived employer safety obligations predicted safety compliance both cross-sectionally (Sample A: $\beta=0.20, \mathrm{p}<0.05$ ) and longitudinally (Sample B: $\beta=0.15, \mathrm{p}<0.05$ ) providing support for Hypotheses 1a. Perceived employer safety obligations predicted safety participation longitudinally in Sample $B(\beta=0.25, \mathrm{p}<0.01)$, but did not predict in Sample A providing only partial support for Hypothesis 1b. Safety attitudes were not significantly predicted by perceived employer safety obligations in either sample, thus, Hypothesis 1c was not supported (see Table 3).

Safety-specific transformational leadership predicted safety compliance both cross-sectionally (Sample A: $\beta=0.13, \mathrm{p}<0.05$ ) and longitudinally (Sample B $\beta=0.24, \mathrm{p}<0.01$ ). Similarly leadership predicted safety participation in both the cross-sectional (Sample A: $\beta=0.29, \mathrm{p}<0.01$ ) and the longitudinal (Sample B: $\beta=0.18, \mathrm{p}<0.01$ ) analyses. Safety attitudes was also predicted by safety specific transformational leadership in both the crosssectional (Sample A: $\beta=0.15, \mathrm{p}<0.01$ ) and the longitudinal (Sample $\mathrm{B} \beta=0.25, \mathrm{p}<0.01$ ) analyses, thereby supporting Hypotheses $2 \mathrm{a}, 2 \mathrm{~b}$ and $2 \mathrm{c}$.

The interaction of perceived employer safety obligations and safety-specific transformational leadership emerged as a significant predictor of safety compliance (cross-sectional Sample A: $\beta=0.14, \mathrm{p}<0.01$; longitudinal Sample B: $\beta=0.06, \mathrm{p}<0.05$ ); safety participation (cross sectional Sample A: $\beta=0.12, \mathrm{p}<0.01$; longitudinal Sample B: $\beta=0.07, \mathrm{p}<0.05$ ) and safety attitudes (crosssectional Sample A: $\beta=0.12, \mathrm{p}<0.01$; longitudinal Sample B: $\beta=0.09, \mathrm{p}<0.01$ ). Thus, Hypotheses $3 \mathrm{a}, 3 \mathrm{~b}$ and $3 \mathrm{c}$ are supported.

To further explore the interactions, the simple slopes for perceived employer safety obligations at high and low levels (1 SD above and below the mean) of safety-specific transformational leadership were plotted. As predicted high levels of safetyspecific transformational leadership enhanced the effect of perceived employer safety obligations on safety compliance, safety participation and safety attitudes in both Sample A and Sample B. Given the similar nature of the interaction in each case we provide figures for Sample A. Figures for Sample B are available from the researchers (see Figs. 1-3).

\section{Discussion}

We extend previous research investigating organizational social exchanges in a safety context by examining the main and interac-

Table 2

Means, standard deviation, and intercorrelations between variables in Sample A and Sample B.

\begin{tabular}{|c|c|c|c|c|c|c|c|c|c|}
\hline Variable & $M$ & $S D$ & 1 & 2 & 3 & 4 & 5 & $M$ & $S D$ \\
\hline 1. Perceived employer safety obligations & 5.22 & 1.20 & & $0.66^{* *}$ & $0.24^{*}$ & 0.07 & -0.01 & 5.36 & 1.17 \\
\hline 2. Transformational safety leadership & 4.58 & 1.55 & $0.66^{* * *}$ & & $0.21^{*}$ & 0.09 & 0.01 & 5.08 & 1.36 \\
\hline 3. Safety compliance & 5.76 & 0.89 & $0.38^{* *}$ & $0.37^{* *}$ & & $0.69^{* *}$ & $0.76^{* *}$ & 5.75 & 0.90 \\
\hline 4. Safety participation & 5.56 & 0.93 & $0.37^{* *}$ & $0.49^{* *}$ & $0.66^{* *}$ & & $0.68^{* *}$ & 5.48 & 0.96 \\
\hline 5. Safety attitudes & 5.87 & 0.82 & $0.35^{* *}$ & $0.34^{* *}$ & $0.73^{* *}$ & $0.72^{* *}$ & & 5.67 & 0.86 \\
\hline
\end{tabular}

Note: Sample A below the diagonal. Sample B above diagonal. ** $p<0.01$ 
Table 3

Results of the moderated regression analysis for Sample A and B.

\begin{tabular}{|c|c|c|c|c|c|c|}
\hline \multirow[t]{2}{*}{ Predictor } & \multicolumn{2}{|c|}{ Safety compliance } & \multicolumn{2}{|c|}{ Safety participation } & \multicolumn{2}{|c|}{ Safety attitudes } \\
\hline & $\beta$ & $S E$ & $\beta$ & SE & $\beta$ & $S E$ \\
\hline \multicolumn{7}{|l|}{ Sample A } \\
\hline Age & 0.02 & 0.01 & $0.02^{* *}$ & 0.01 & $0.02^{* *}$ & 0.01 \\
\hline Perceived employer obligations & $0.20^{*}$ & 0.08 & 0.08 & 0.09 & 0.14 & 0.08 \\
\hline Transformational leadership & $0.13^{* *}$ & 0.07 & $0.29^{* * *}$ & 0.07 & $0.15^{* *}$ & 0.06 \\
\hline Interaction term & $0.14^{* *}$ & 0.04 & $0.12^{* *}$ & 0.04 & $0.12^{* *}$ & 0.04 \\
\hline$R^{2}$ & $0.23^{* *}$ & & $0.36^{* *}$ & & $0.31^{* *}$ & \\
\hline$\Delta R^{2}$ & $0.08^{* *}$ & & $0.05^{* *}$ & & $0.07^{* *}$ & \\
\hline \multicolumn{7}{|l|}{ Sample B } \\
\hline Age & 0.02 & 0.01 & 0.02 & 0.01 & 0.02 & 0.02 \\
\hline Gender & 0.29 & 0.25 & -0.12 & 0.25 & 0.22 & 0.23 \\
\hline Time 1 safety compliance & $0.38^{* *}$ & 0.07 & & & & \\
\hline Time 1 safety participation & & & $0.51^{* *}$ & 0.07 & & \\
\hline Time 1 safety attitudes & & & & & $0.42^{* *}$ & 0.07 \\
\hline Perceived employer obligations & $0.15^{*}$ & 0.08 & $0.25^{* *}$ & 0.07 & $0.08^{* *}$ & 0.07 \\
\hline Transformational leadership & $0.24^{* *}$ & 0.07 & $0.18^{* *}$ & 0.06 & $0.25^{* *}$ & 0.06 \\
\hline Interaction term & $0.06^{*}$ & 0.03 & $0.07^{*}$ & 0.03 & & \\
\hline$R^{2}$ & $0.49^{* *}$ & & $0.50^{* *}$ & & $0.31^{* *}$ & \\
\hline$\Delta R^{2}$ & $0.02^{*}$ & & $0.03^{*}$ & & $0.07^{* *}$ & \\
\hline
\end{tabular}

ns = non-significant at $p=0.05$ level; interaction term = cross product of perceived employer safety obligations and safety-specific transformational leadership. ${ }^{*} p<0.05$.

** $p<0.01$.

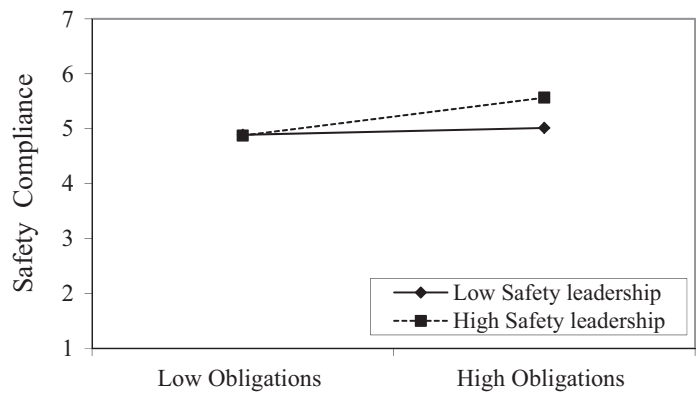

Fig. 1. Interaction of perceived employer safety obligations and safety-specific transformational leadership predicting safety compliance in Sample A.

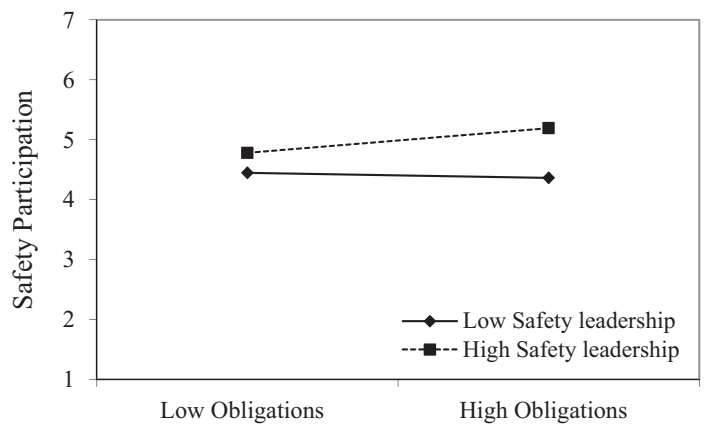

Fig. 2. Interaction of perceived employer safety obligations and safety-specific transformational leadership predicting safety participation in Sample A.

tive effects of perceived employer safety obligations and safetyspecific transformational leadership on employee safety attitudes and behavior. This study extends previous qualitative research by empirically testing the relationship between perceived employer safety obligations and employee safety behavior and attitudes. As predicted, we found that when employers are perceived to have fulfilled safety-related obligations, employees tend to reciprocate with positive safety performance behaviors. Furthermore, we contribute to the extant research demonstrating that transformational leadership predicts employee safety behavior (Clarke, 2013).

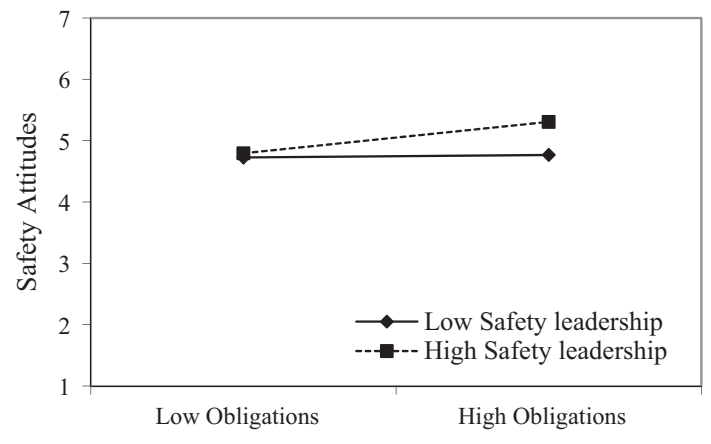

Fig. 3. Interaction of perceived employer safety obligations and safety-specific transformational leadership predicting safety attitudes in Sample A.

Our findings provide a unique contribution and we demonstrate that safety-specific transformational leadership strengthens the positive relationship between employer safety obligations and employee safety compliance, safety participation and safety attitudes. In the case of employee safety compliance and safety participation, the interaction between perceived employer obligations and safety-specific transformational leadership accounted for unique incremental variance beyond the significant main effects. For employee safety attitudes, contrary to our hypothesis, the main effect of perceived employer safety obligations was not significant. However, the interaction term (perceived employer safety obligations and safety-specific transformational leadership) significantly predicted employee safety attitudes and the results show that the relationship between perceived employer safety obligations and employee safety attitudes becomes stronger and significant under high levels of safety-specific transformational leadership. Although research on safety climate implies that safety attitudes are not as important as other predictors, the results suggest that attitudes are important for understanding how the mechanism of safety influence works.

Although interaction effects are typically small in magnitude (typically accounting for $1-3 \%$ of criterion variance, Aiken and West, 1991), the effects we found were more substantial with the interactions accounting for $5-8 \%$ of criterion variance. Moreover, we replicated our findings for the interaction effects across 
two independent samples and safety outcomes, demonstrating a robust relationship. Replication is particularly important in this case because with the second sample we were able to implement time one outcomes as control variables in the analysis. Thus our data show that the interaction predicts the outcomes (Sample A) but also that the interactions predicted the change in outcome variables from time one to time two (Sample B).

In light of these findings it is important for organizations to recognize that legislated employer health and safety responsibilities (i.e., providing safety training, maintaining equipment, etc.) may be important for improving workplace safety behavior. However, the positive effects of legislated employer safety obligations appear to be stronger when leaders within the organization are perceived to promote safety and engage in effective safety leadership behavior. Our data suggest that the positive relationship between perceived employer safety obligations and safety attitudes is attenuated under low levels of safety-specific transformational leadership. Thus, is important for organizations to recognize that the success of safety programs and policies depend on effective safety leaders.

Our results are consistent with previous research demonstrating that workplace safety may be shaped by various organizational safety influences including management's concern for safety (Griffin and Neal, 2000), leader safety practices (Hofmann and Morgeson, 1999; Zohar and Polachek, 2014; Kelloway et al., 2006; Mullen et al., 2011) and the priority an organization places safety (Katz-Navon et al., 2005). Researchers have also shown that leader safety practices buffer the negative effects of organizational and individual influences on safety performance (Kao et al., 2015; Zohar and Luria, 2010). Building on this research, we demonstrate the enhancing effect of leader behavior when combined with other organizational safety influences. Employer safety obligations signal to employees that the organization values safety and is concerned about the health and well-being of employees. Furthermore, leaders play a critical role in communicating (and modeling) the organizational safety values, also signaling to employees the value that is placed on safety. The perception that both the employer and the organizational leaders value safety is reciprocated through positive attitude and behavioral responses toward safety. Similar to the "buffering effect" of leader safety practices on the relationship between negative safety influences and safety outcomes, our results suggest that better safety outcomes result when employees perceive that their employer has fulfilled safety obligations and when their leader displays safety-specific transformational leadership behavior.

\subsection{Practical implications}

Our results provide support for the function and purpose of occupational health and safety legislation and employer safety responsibilities. Despite safety policies and practices being mandated by occupational health and safety acts, to our knowledge previous researchers have not empirically examined the relationship between employer responsibilities and safety behavior. At the very minimum, fulfilling employer safety-related responsibilities are intended as a safeguard against accidents and injuries. Our results suggest that fulfilled employer safety obligations indeed are one contributing factor to workplace safety through positive employee safety performance behavior.

Leaders play an essential role in promoting safety within organizations. Safety transformational leadership behavior within organizations was shown to enhance the positive effects attained through safety policies and practices that are mandated by occupational health and safety legislation. In the context of safety, organizational influences (and their combined interactive effects) that enhance employee safety performance behavior and attitudes are extremely important given that safety behavior is directly associated with risks of injuries and accidents (Clarke, 2013; Neal and Griffin, 2006).

Our findings provide further empirical evidence that may be utilized for developing evidence-based safety interventions. Interventions studies suggest that employee safety outcomes may be enhanced through safety leadership training (i.e., Zohar and Polachek, 2014). For example, in a quasi-experimental study, Sivanathan et al. (2005) demonstrated that a safety-specific transformational leadership training intervention for supervisors (including a booster session) significantly improved swim instructor safety participation and maintained the level of safety compliance behavior. These results are encouraging and there remains a need for safety leadership intervention studies to assess the impact of specific safety leadership behavior (i.e., transformational, transactional, supportive, etc.) and the features of the intervention (i.e., lecture based, goal setting, feedback, etc.) to determine whether leaders may improve their safety leadership and to identify safety leadership behaviors that promote employee safety compliance and participation.

\subsection{Potential limitations and future research}

This study has several potential limitations. First, the use of questionnaires to gather self-report data on safety-specific leadership behaviors, safety performance behaviors and attitudes creates the potential for mono-method bias. Common method variance may be an alternative explanation of the main effects found in this study, however, it is an extremely unlikely explanation for the interaction effects found across our samples (Siemsen et al., 2010) as it is likely to attenuate rather than create interaction effects (Evans, 1985). Despite the unlikelihood that common method variance explains our results, collecting data from different sources (i.e., leader ratings of employee safety performance behavior) to reduce common method variance is recommended (Podsakoff et al., 2003).

The findings of Sample A based on cross-sectional survey data thus limiting causal inferences. However, there is a significant body of research that demonstrating the robust relationship between transformational leadership and safety performance behavior (Clarke, 2013; Hoffmeister et al., 2014; Kelloway et al., 2006; Mullen et al., 2011). In Sample B, we obtained measures of employee safety participation, safety compliance and safety attitudes at time 1 prior to completing the work practicum and again at Time 2 (upon completion of the practicum). The longitudinal design allowed us to demonstrate that the interaction effects of interest predicted the change in the outcome variables (i.e., compliance, participation and safety attitudes). Future research should focus on obtaining a more complete longitudinal analysis of these effects, involving at least three waves of data collection.

Another potential limitation of the current research is the degree to which the findings may be generalized to various occupations and organizational settings. Our samples involved individuals at various stages of trades training. However, future studies that empirically evaluate the relationships between perceived employer safety obligations, safety-specific leadership and the employee safety outcomes with in different occupational settings, and with different age, groups, are warranted.

Researchers should continue to examine how different safety leadership behaviors interact with employer safety obligations to influence employee safety behavior and attitudes. For example, researchers have shown a positive influence of both transactional leadership (i.e., Zohar, 2002) and supportive leadership behavior (Mullen and Rheaume-Brüning, 2015) on employee safety behavior. Griffin and Hu (2013) found that safety inspiring behavior is related to safety participation, whereas safety monitoring behavior 
is strongly associated with safety compliance. In other research, leader idealized influence (i.e., communicate values, respected and trusted by employees) emerged as the most important predictor of safety performance behavior (Hoffmeister et al., 2014). Therefore, it would be beneficial to determine whether the combination of different styles of leadership (i.e., transformational, transactional and supportive leadership) or specific safety leadership behaviors (i.e., inspiring, individualized consideration, etc.) have enhancing and/or differential effects on the relationship between employer safety obligations and employee safety outcomes.

In addition to examining organizational safety influences, future studies should examine alternative models that outline the underlying processes that explain workplace safety behavior. For example, Hale and Borys (2013) provide a review of both top-down and bottom-up models of safety rules and procedures to highlight the gap between the realities of work and the rules that guide safe work behavior. In their review of the safety literature, they highlight the complexities, and often taken for granted assumptions, relating to the study of workplace safety behavior and provide a comprehensive framework as a guide for future research.

Lastly, we build on the extant literature that empirically examines safety reciprocity as the underlying mechanism that contributes to our understanding of employee safety behavior. However, we recognize that researchers should continue to develop and empirically test competing theoretical models that help explain employee safety performance. Again, Hale and Borys (2013) provide a useful theoretical framework to guide this area of research.

\section{Conclusion}

This study provides significant contributions to the occupational safety literature by examining the moderating effects of safety-specific transformational leadership on the relationship between perceived employer safety obligations, safety performance behavior and safety attitudes. We tested our hypotheses across two independent samples and found that the relationships between perceived employer safety obligations and the safety outcomes were stronger when safety-specific transformational leadership was high. Thus, we conclude that both employer safety responsibilities and leaders play an important role in creating a safe work environment and hope that these findings help organizations develop safety interventions and practices.

\section{References}

Aiken, L.A., West, S.G., 1991. Multiple Regression: Testing and Interpreting Interactions. Sage, Newbury Park, CA.

Barling, J., Loughlin, C., Kelloway, E.K., 2002. Development and test of a model linking safety-specific transformational leadership and occupational safety. J. Appl. Psychol. 87, 488-496. http://dx.doi.org/10.1037//0021-9010.87.3.488.

Bass, B.M., 1985. Leadership and Performance Beyond Expectations. Free Press, New York, NY.

Bass, B.M., Avolio, B.J., 1997. Full Range Leadership Development: Manual for the MLQ. Mind Garden, Palo Alto, CA.

Blau, P.M., 1964. Exchange and Power in Social Life. Wiley, New York.

Burt, C.D., Williams, S., Wallis, D., 2012. New recruit safety expectations: relationships with trust and perceived job risk. Saf. Sci. 50, 1079-1084. http:// dx.doi.org/10.1016/j.scci.2011.11.019.

Christian, M.S., Bradley, J.C., Wallace, J.C., Burke, M.J., 2009. Workplace safety: a meta-analysis of the roles of person and situation factors. J. Appl. Psychol. 94, 1103-1127. http://dx.doi.org/10.1037/a0016172.

Clarke, S., 2006. The relationship between safety climate and safety performance: a meta-analytic review. J. Occup. Health Psychol. 11, 315-327.

Clarke, S., 2013. Safety leadership: a meta-analytic review of transformational and transactional leadership styles as antecedents of safety behaviours. J. Occup. Organizational Psychol. 86, 22-49.

Clarke, S., Ward, K., 2006. The role of leader influence tactics and safety climate in engaging employees' safety participation. Risk Anal. 26 (5), 1175-1185. http:// dx.doi.org/10.1111/j.1539-6924.2006.00824.x
Cree, T., Kelloway, E.K., 1997. Responses to occupational hazards: exit and participation. J. Occup. Health Psychol. 2 (4), 304-311. http://dx.doi.org/ 10.1037/1076-8998.2.4.304.

Evans, M.G., 1985. A Monte Carlo study of the effects of correlated method variance in moderated multiple regression analysis. Organizational Behav. Hum. Decision Processes 36 (3), 305-323.

Gouldner, A.W., 1960. The norm of reciprocity: a preliminary statement. Am. Sociol. Rev. 25, 161-178.

Griffin, M.A., Hu, X., 2013. How leaders differentially motivate safety compliance and safety participation: the role of monitoring, inspiring, and learning. Saf. Sci. 60, 196-202.

Hale, A., Borys, D., 2013. Working to rule of working safely? Part 1: a state of the art review. Saf. Sci. 55, 201-221.

Hayes, A., 2013. Introduction to Mediation, Moderation and Conditional Process Analysis: A Regression-Based Approach. The Guilford Press, New York.

Hofmann, D.A., Morgeson, F.P., 1999. Safety-related behavior as a social exchange: the role of perceived organizational support and leader-member exchange. J. Appl. Psychol. 84 (2), 286-296. http://dx.doi.org/10.1037/0021-9010.88.1.170.

Hofmann, D.A., Morgeson, F.P., Gerras, S.J., 2003. Climate as a moderator of the relationship between leader-member exchange and content specific citizenship: safety climate as an exemplar. J. Appl. Psychol. 88 (1), 170-178.

Hoffmeister, K., Gibbons, A.M., Johnson, S.K., Cigularov, K.P., Chen, P.Y., Rosecrane, J. C., 2014. The differential effects of transformational leadership facets on employee safety. Saf. Sci. 62, 68-78. http://dx.doi.org/10.1016/j.ssci.2013.004.

Kao, K., Spitzmueller, C., Cigularov, K., Wu, H., 2015. Linking insomnia to workplace injuries: a moderated mediation model of supervisor safety priority and safety behavior. J. Occup. Health Psychol. http://dx.doi.org/10.1037/a0039144.

Kath, L.M., Marks, K.M., Ranney, J., 2010. Safety climate dimensions, leader-member exchange, and organizational support. Saf. Sci. 48, 643-650. http://dx.doi.org/ 10.1016/j.ssci.2010.01.016.

Katz-Navon, T., Naveh, E., Stern, Z., 2005. Safety climate in healthcare organizations: a multidimensional approach. Acad. Manage. J. 48, 1073-1087. http://dx.doi. org/10.5465/AMJ.2005.19573110.

Kelloway, E.K., Francis, L., Schat, A., Iverson, R., 2005. Family socialization of young workers' safety attitudes. In: Paper presented at the Annual Meeting of the Society for Industrial/Organizational Psychology, Los Angeles, CA.

Kelloway, E.K., Mullen, J.E., Francis, L., 2006. Injuring your leadership: how passive leadership affects employee safety. J. Occup. Health Psychol. 11 (1), 76-86.

McLain, D.L., 2014. Sensitivity to social information, social referencing, and safety attitudes in a hazardous occupation. J. Occup. Health Psychol. 19 (4), 425-436. http://dx.doi.org/10.1037/a0037126.

Mullen, J.E., Kelloway, E.K., Teed, M., 2011. Inconsistent leadership. Work Stress J. 25 (1), 41-54.

Mullen, J., Rheaume-Brüning, A., 2015. The interactive effects of fatigue and leadership on employee safety behavior. In: Poster Session Presented at the Work, Stress and Health Conference, Atlanta, Georgia.

Nahrgang, J.D., Morgeson, F.P., Hofmann, D.A., 2007. Predicting safety performance behavior: a meta-analysis of safety and organizational constructs. In: Poster Session Presented at the 22nd Annual Conference of the Society for Industrial and Organizational Psychology, New York, NY.

Neal, A., Griffin, M.A., 2003. Safety climate and safety at work. In: Barling, J., Frone, M. (Eds.), The Psychology of Workplace Safety. American Psychological Association, Washington, DC, USA.

Neal, A., Griffin, M.A., 2006. A study of the lagged relationships among safety climate, safety motivation, safety behavior, and accidents at the individual and group levels. J. Appl. Psychol. 91 (4), 946-953. http://dx.doi.org/10.1037/00219010.91.4.946.

Neal, A., Griffin, M.A., Hart, P.M., 2000. The impact of organizational climate and individual behavior. Saf. Sci. 34 (3), 99-109.

Podsakoff, P.M., MacKenzie, S.B., Lee, J.Y., Podsakoff, N.P., 2003. Common method biases in behavioral research: a critical review of the literature and recommended remedies. J. Appl. Psychol. 88, 879-903. http://dx.doi.org/ 10.1037/0021-9010.88.5.879.

Rousseau, D.M., 1989. Psychological and implied contracts in organizations. Empl. Responsibilities Rights J. 2, 121-139.

Rousseau, D.M., 1990. New hire perceptions of their own and their employer's obligations: a study of psychological contracts. J. Organizational Behav. 11, 389-400.

Siemsen, E., Roth, A., Oliveira, P., 2010. Common method variance in regression models with linear, quadratic and interaction effects. Organizational Res. Methods 13, 456-476.

Sivanathan, N., Turner, N., Barling, J., 2005. Effects of transformational leadership training on employee safety performance. A quasi-experiment study. In: Academy of Management Annual Meeting Proceedings. pp. 1-6. http://dx.doi. org/10.5465/AMBPP.2005.18780756.

Tucker, S., Turner, N., 2015. Sometimes it hurts when supervisors don't listen: the antecedents and consequences of safety voice among young workers. J. Occup. Health Psychol. 20 (1), 72-81. http://dx.doi.org/10.1037/a0037756.

Walker, A., 2010. The development and validation of a psychological contract of safety scale. J. Saf. Res. 41, 315-321.

Walker, A., Hutton, D.M., 2006. The application of the psychological contract to workplace safety. J. Saf. Res. 37, 433-441. http://dx.doi.org/10.1016/j. jsr.2006.06.001.

Zohar, D., 2000. A group-level model of safety climate: testing the effect of group climate on microaccidents in manufacturing jobs. J. Appl. Psychol. 85 (4), 587596. http://dx.doi.org/10.1037/0021-9010.85.4.587. 
Zohar, D., 2002. The effects of leadership dimensions, safety climate, and assigned priorities on minor injuries in work groups. J. Organizational Behav. 23, 75-92.

Zohar, D., Polachek, T., 2014. Discourse-based intervention for modifying supervisory communication as leverage for safety climate and performance improvement: a randomized field study. J. Appl. Psychol. 99 (1), 113-124. http://dx.doi.org/10.1037/a0034096.
Zohar, D., Luria, G., 2010. Group leaders as gatekeepers: testing safety climate variations across levels of analysis. Appl. Psychol.: Int. Rev. 59 (4), 647-673. http://dx.doi.org/10.1111/j.1464-0597.2010.00421.x.

Zohar, D., Tenne-Gazit, O., 2008. Transformational leadership and group interaction as climate antecedents: a social network analysis. J. Appl. Psychol. 93, 744-757. http://dx.doi.org/10.1037/0021-9010.93.4.744. 